\title{
Utilidad de los parámetros analíticos en el diagnóstico de las enfermedades hepáticas
}

\author{
A. MORENO BORQUE, L. GONZÁLEZ MORENO'1, J. MENDOZA-JIMÉNEZ1', \\ L. GARCÍA-BUEY' ${ }^{1}$ R. MORENO OTERO ${ }^{1}$
}

Servicio de Anestesiología y Reanimación. Hospital Ramón y Cajal. Universidad de Alcalá de Henares. ${ }^{I}$ Servicio de Aparato Digestivo. Hospital Universitario de la Princesa. Universidad Autónoma de Madrid

UTILTY OF ANALITICAL PARAMETERS IN THE DIAGNOSIS OF LIVER DISEASES

\section{RESUMEN}

Las pruebas de función hepática incluyen tanto test bioquímicos (AST, ALT, GGT o fosfatasa alcalina), así como niveles de bilirrubina sérica, albúmina o pruebas de coagulación como la actividad de protrombina. La gran frecuencia con la que estas pruebas son incluidas en exámenes de rutina, tanto de pacientes sintomáticos como asintomáticos, hace que sea de vital importancia la correcta evaluación de los resultados.

Elevación de enzimas de predominio citolítico: En elevaciones crónicas, leves-moderadas, se debería descartar toxicidad por fármacos, hepatopatías virales, alcohólicas, hemocromatosis o esteatosis no alcohólica.

Elevación de predominio colestásico: La primera evaluación debería valorar el origen de la fosfatasa alcalina, siendo la medición conjunta de la GGT la mejor forma de confirmar el origen hepático de la fosfatasa alcalina. El siguiente paso consiste en determinar la presencia de colestasis extrahepática (por obstrucción biliar de cualquier causa) o intrahepática (CBP, CEP, fármacos, etc.). En estos casos la primera prueba a realizar será una ecografía abdominal, que va a permitir evaluar la vía biliar.

Hiperbilirrubinemia: En caso de hiperbilirrubinemia no conjugada se debe valorar las distintas causas (hemolisis, eritropoyesis ineficaz, síndrome de Gilbert o Criggler-Najjar). La hiperbilirrubinemia conjugada aislada, es una situación más infrecuente, y debe hacer pensar en síndromes como el de Rotor o de Dubin-Johnson.

La evaluación de los niveles de albúmina y de protrombina van a evaluar la función hepática per se, permitiendo distinguir entre procesos agudos y crónicos.

No existen en la actualidad estudios prospectivos que evalúen la eficacia de estos test de función hepática. La realización de una historia clínica detallada, una exploración física adecuada y de pruebas diagnósticas no invasivas (serologías, perfil férrico, autoinmunidad o ecografía abdominal) va a permitir diagnosticar la mayoría de las patologías causantes de la alteración, quedando en segundo lugar pruebas más complejas incluyendo la realización de una biopsia hepática.

PALABRAS CLAVE: Pruebas de función hepática. ALT. AST. Fosfatasa alcalina. Gammaglutamil transpeptidasa. Virus de la hepatitis B. Virus de la hepatitis C. Hepatitis autoinmune.

\section{ABSTRACT}

Liver function tests include biochemical parameters (AST, ALT, GGT or Alkaline phosphatase), bilirrubin and albumin levels and coagulation tests as prothrombin activity. These tests are commonly used in the routine screening even in symptomatic as in asymptomatic patients, and the right evaluation of the results is of vital importance.

Citolytic elevation in serum aminotransferases: In mild chronic elevation pharmacological toxicity, viral hepatitis, alcoholic and non-alcoholic fatty liver disease and hemochromatosis, should be excluded.

Cholestatic elevation os serum enzymes: The first option should be to establish the origin of the alkaline phosphatase elevation, with the evaluation of the GGT levels to confirm the hepatic origin. The next step should be to distinguish the presence of an extrahepatic (biliary obstruction) or intrahepatic (PBC, PSC, drugs, etc) cholestasis, in these cases the most important test shoul be the abdominal ultrasound, in order to evaluate the biliary system.

Hyperbilirrubinemia: Non conjugated hyperbilirrubinemia (hemolysis, ineffective eritropoyesis, Gilbert or Criggler-Najjar syndromes) and conjugated hyperbilirrubinemia, an unusual situation in wich Rotor and Dubin-Johnson Syndromes should be considered.

The evaluation of albumin and prothrombin levels evaluates the hepatic function per se, allowing to differentiate between acute and chronic diseases.

At present, there are not prospective studies to evaluate the efficacy of the liver function tests. To carry out a complete medical history, an appropiate physical examination and the appropriate application of noninvasive diagnostic test (serology, iron levels, autoimmunity or abdominal ultrasound) allow to perform a right diagnosis in most patients, making more complex tests, including liver biopsy, secondary.

KEY WORDS: Liver function test. ALT. AST. Alkaline phosphatase. Gamma-glutamil transpeptidase. Hepatitis $B$ virus. Hepatitis $C$ virus. Autoimmune hepatitis. 


\section{INTRODUCCIÓN}

Dentro de los denominados test de función hepática (TFH) se incluyen varios parámetros bioquímicos como son la aspartato aminotransferasa (AST), alanino aminotransferasa (ALT), gammaglutariltranspeptidasa (GGT), fosfatasa alcalina (FA), bilirrubina, albúmina y actividad de protrombina. Sin embargo, dicha terminología no es del todo exacta ya que de todos ellos, sólo los tres últimos miden la capacidad funcional del hígado, siendo los demás potenciales indicadores de daño hepático.

Debido a la gran frecuencia con que dichos test son incluidos dentro de programas de screening, tanto de pacientes sintomáticos como asintomáticos, un problema habitual en la práctica clínica consiste en realizar una correcta interpretación de los resultados obtenidos.

Para ello, en primer lugar hay que tener en cuenta que el rango de normalidad para cualquier test de laboratorio, se encuentra en el intervalo comprendido entre \pm 2 desviaciones estándar en relación al valor medio obtenido a partir de una población sana de similares características. Según este criterio, hasta un $5 \%$ de la población sana a la que se solicitan pruebas de función hepática presentan al menos un valor alterado. Por otra parte, unos resultados normales no excluyen con total seguridad la existencia de patología hepática. Dos ejemplos de ello son la hepatitis crónica por VHC en la que es característico la existencia de un patrón fluctuante en los valores de las transaminasas a lo largo del tiempo o bien la cirrosis avanzada donde podemos encontrar un perfil hepático dentro de los valores normales.

En segundo lugar, los parámetros incluidos en dichos test no son órgano-específicos y pueden reflejar tanto patología hepática como a otros niveles. Así, podemos encontrar hiperbilirrubinemia aislada en casos de hemólisis, elevaciones de la fosfatasa alcalina sin otros parámetros hepáticos alterados en casos de patología ósea o elevaciones de la ALT tras ejercicio físico, patología muscular o hipotiroidismo $(1,2)$.

De todo esto se deduce, que una adecuada interpretación de los resultados de cualquier test de función hepática debe ir siempre precedida de una rigurosa historia clínica en la que se recojan los síntomas y signos que presenta el paciente, realizando especial hincapié en potenciales factores de riesgo sexual o parenteral (transfusión, consumo de drogas por vía parenteral, etc.), existencia de enfermadades concomitantes y consumo de alcohol, fármacos o productos de herboristería.

En aquellos casos en los que encontremos datos clínicos que orienten hacia una determinada patología concreta se realizaran los test serólogicos y pruebas complementarias que permitan confirmar dicho diagnóstico.

Sin embargo, en un porcentaje no despreciable de casos el paciente se encuentra asintomático y no existen datos en la anamnesis que nos permitan realizar un diagnóstico de presunción. Es en estas situaciones, en las que basándonos en las características de cada sujeto (sexo, edad, raza, patología concomitante ,etc...) y grado de alteración de los TFH deberemos plantearnos cual sería la conducta más apropiada desde un punto de vista coste-efectivo.

Son numerosos los estudios realizados para conocer cuales son la causas más frecuentes de hepatopatía en pacientes asintomáticos con elevación de alguno de los test de función hepática. En la mayoría de los casos, tras completar el estudio mediante múltiples test serológicos y biopsia hepática la pato- logía más frecuente encontrada fue la esteatosis hepática(hasta un $40 \%$ ) existiendo un porcentaje no despreciable de casos (hasta $25 \%$ en algunos estudios) donde la biopsia no aportó ningún dato que orientara hacia un diagnostico etiológico concreto (3).

A continuación se realiza una breve revisión sobre la conducta a seguir ante un paciente asintomático con alteración de los TFH.

Desde un punto de vista conceptual los trastornos en la pruebas de función hepática se pueden dividir en dos grandes grupos:

-Patrón citolítico: en el que predomina la elevación de la transaminasas.

-Patrón colestásico: elevación preponderante de la fosfatasa alcalina, generalmente acompañado de aumento de la gammaglutariltranspeptidasa con o sin elevación de la bilirrubina.

CONDUCTA A SEGUIR EN PACIENTES CON ELEVACIÓN CRÓNICA LEVE-MODERADA DE TRANSAMINASAS ( $<5$ VECES EL LÍMITE NORMAL) (Fig. 1)

Dentro de este grupo por su mayor prevalencia se deberían descartar en primer lugar hepatotoxicidad por fármacos, hepatopatías virales, hepatopatía alcohólica hemocromatosis hereditaria y esteatohepatitis no alcohólica.

Como consecuencia del envejecimiento progresivo de la población y de la exposición a nuevos fármacos, la incidencia de hepatotoxicidad está aumentando en los últimos años(4). Se estima que se diagnostican aproximadamente un $10 \%$ de los casos reales. Esto es debido a que en muchas ocasiones el paciente se encuentra asintomático, no existen pruebas diagnósticas específicas y a que prácticamente cualquier fármaco puede ser potencialmente hepatotóxico. Por tanto, ante un paciente polimedicado con elevación de transaminasas se debe retirar cualquier fármaco que no sea imprescindible para el paciente. En caso contrario, se intentará sustituir por otro con menor potencial hepatotóxico y si esto no fuera posible se debe valorar de forma individualizada el riesgo - beneficio que supone en cada caso continuar o suspender el fármaco. $\mathrm{Si}$ se opta por continuar el tratamiento se debe llevar a cabo un estrecha vigilancia del paciente realizando controles analíticos periódicos. Si la elevación de transaminasas es mantenida y /o progresiva en el tiempo se debería retirar el fármaco debido al riesgo aumentado que presentan estos pacientes para desarrollar un fallo hepático fulminante.

El consumo excesivo de alcohol continúa siendo hoy en día una de las principales causas de hepatopatía en nuestro medio debido en gran parte a su disponibilidad y accesibilidad, a una legislación permisiva sobre su consumo y a condiciones culturales.

La relación del alcoholismo con el hígado graso fue descrita por primera vez por Addison en 1836. Desde entonces, son numerosos los estudios epidemiológicos que han puesto de manifiesto una clara relación entre el consumo excesivo de alcohol y el desarrollo de cirrosis.

En la mayoría de los casos, el diagnóstico de abuso de alcohol puede ser complicado ya que los pacientes lo niegan. Por tanto, en estos casos es fundamental realizar un adecuado interrogatorio a familiares o personas del entorno del paciente. Se considera consumo excesivo de alcohol aquel superior a 

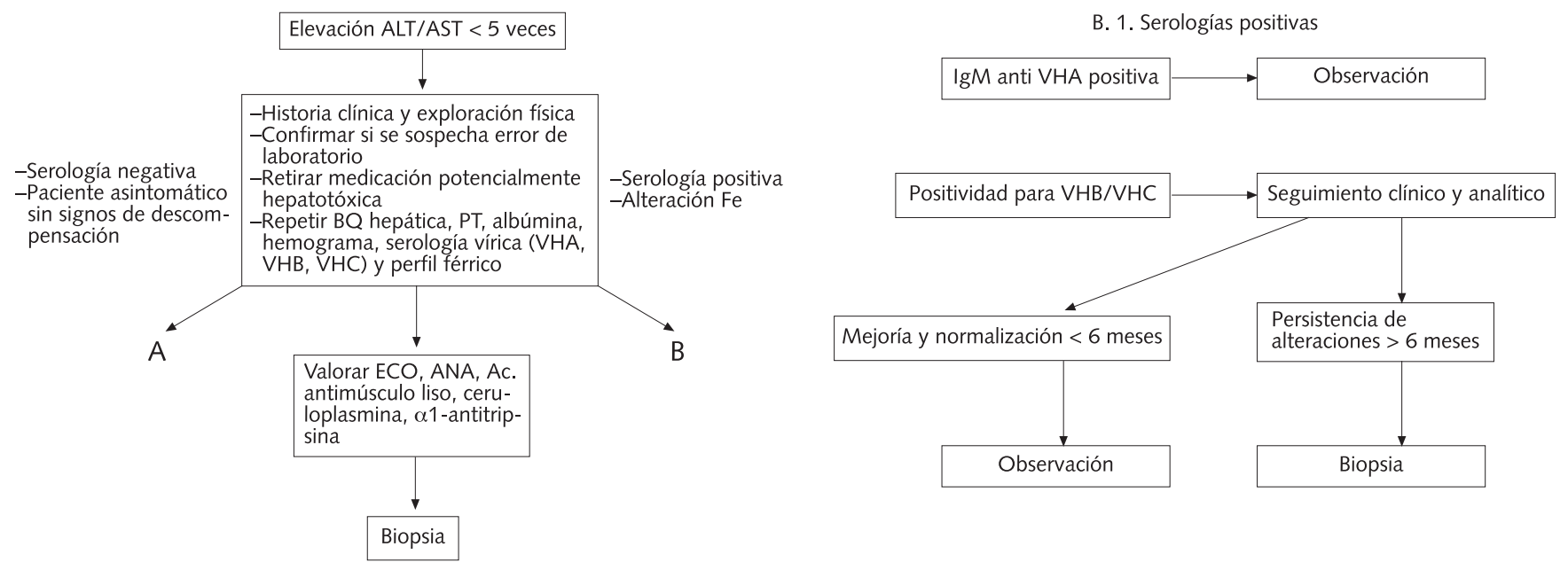

A. Resultados negativos. Paciente sintomático, sin signos de descompensación

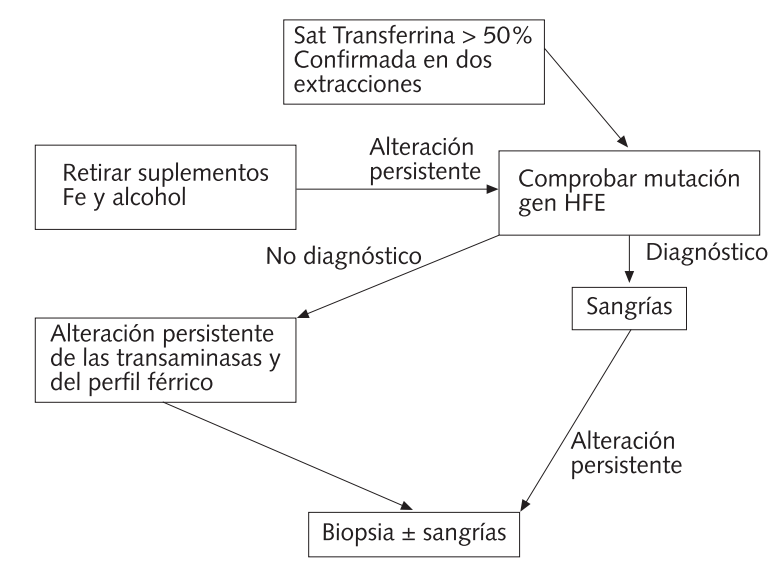

Fig. 1. Algoritmo diagnóstico para la elevación crónica leve-moderada de enzimas hepáticas. (Modificado de Green et al.) (21). BQ: bioquímica; PT: actividad de protrombina; ANA: anticuerpos anti-nucleares; ECO: ecografía abdominal.

40gr/día en mujeres y 60 gr/día en hombres en los últimos seis meses. Para calcular la cantidad de alcohol se aplica la siguiente fórmula: (Volumen $\left(\mathrm{cm}^{3}\right) \mathrm{x}$ graduación de la bebida alcohólica x 0,8)/100

Tanto la cantidad como el tiempo de consumo son variables fundamentales en cuanto al riesgo de desarrollar lesión hepática. El espectro de lesión es amplio e incluye desde esteatosis hepática, cuya frecuencia asciende al 90-100\% de los bebedores severos, hepatitis aguda alcohólica $10-35 \%$ o cirrosis en el $8-10 \%$ de los casos. Hay que tener en cuenta que se trata de un proceso dinámico y que por tanto en un mismo paciente pueden darse los tres tipos de lesión simultáneamente.

No obstante, existen una serie de parámetros bioquímicos relacionados con el consumo excesivo de alcohol que nos pueden permitir establecer una elevada sospecha de hepatopa- tía alcohólica.

Un cociente GOT/GPT > 2 es altamente sugerente de daño hepático por alcohol. Los niveles de GOT rara vez son superiores a $300 \mathrm{UI} / \mathrm{ml}$. Sin embargo, estos hallazgos no son patognomónicos para esta patología y también se han descrito en algunos casos de esteatohepatitis no alcohólica o en pacientes con infección crónica por VHC en estadío cirrótico.

Otros marcadores bioquímicos característicos aunque no específicos alcoholismo son la elevación de la GGT > 2, hipertrigliceridemia, hiperuricemia, y la macrocitosis con un $\mathrm{VCM}<100 \mu \mathrm{m}^{3}$.

La infección crónica por los virus de la hepatitis B y C constituyen hoy en día una de las principales causas de hepatopatía crónica en nuestro medio. En ambos casos son patologías paucisíntomáticas por lo que constituyen una causa frecuente de elevación asintomática de trsansaminasas. 
Se estima que aproximadamente entre un $1 \%$ y un $2 \%$ de la población española se encuentra infectada por el virus de la hepatitis C (VHC) y entre un $0,1-2 \%$ son portadores del VHB. En ambos casos es frecuente que exista un ligero predominio en la elevación de la GPT sobre la GOT.

Por tanto, a todo paciente con elevación asintomática de transaminasas se le debe interrogar sobre potenciales factores de riesgo sexual o parenteral para adquisición de hepatitis $\mathrm{C}$ o hepatitis B.

La primera prueba que se debe realizar para confirmar una infección por VHC es la presencia de anticuerpos anti-VHC mediante test de ELISA que presenta una sensibilidad del 9297\%. La positividad del anticuerpo de VHC en pacientes con factores de riesgo es suficiente para establecer el diagnóstico de hepatitis crónica por VHC. En estos casos el siguiente paso consiste en determinar la existencia de replicación viral mediante PCR-VHC, así como el genotipo viral y biopsia hepática para poder plantear la indicación de tratamiento.

Dado que el test de ELISA presenta falsos positivos, en pacientes sin factores de riesgo un resultado positivo debe ser tomado con cautela y confirmado mediante otras pruebas como el inmunoblot (RIBA o similares) o mediante la determinación de RNA-VHC.

Por el contrario en algunos casos como son pacientes inmunosuprimidos el test puede presentar falsos negativos. De este modo, si la sospecha es alta para infección por VHC se debe confirmar el resultado mediante una determinación cualitativa de RNA-VHC.

La probabilidad pretest para hepatitis B se encuentra aumentada entre pacientes con factores de riesgo sexual y/o parenteral, así como en sujetos procedentes de áreas de elevada endemicidad como el sudeste asiático, Afica Subsahariana o China. Para realizar el diagnóstico de infección por VHB, en primer lugar se debe confirmar la positividad al Ag HBs. La persistencia del mismo más de 6 meses permite establecer el diagnóstico de infección crónica del VHB $(5,6)$. A continuación se deberá determinar si el virus se encuentra en fase replicativa. Los marcadores serológicos que nos van a permitir conocer dicha condición son el Ag HBe (en el caso de la cepa salvaje) y la presencia de DNA-VHB en suero (en el caso de mutantes pre-core ).

Existen diferentes métodos para determinar el DNA-VHB sérico; si se utilizan métodos poco sensibles como la hibridación molecular, se pueden obtener resultados falsos negativos mientras que por el contrario, técnicas muy sensibles como la reacción en cadena de la polimerasa, pueden ofrecer resultados falsos positivos en portadores del VHB en los que la replicación del VHB no tiene repercusión clínica. Actualmente se consideran subsidiarios de tratamiento aquellos portadores con niveles de viremia $>105$ copias $/ \mathrm{ml}$ (6).

La positividad para el Ac HBs indica inmunidad frente al VHB por lo que deben buscarse otras causas que expliquen la elevación de transaminasas en ese paciente.

Por último, la positividad del $\mathrm{Ag} \mathrm{HBs}$ con $\mathrm{Ag} \mathrm{HBe}$ negativo y DNA-VHB negativo nos indica que el paciente es portador sano del VHB, situación que no justificaría una elevación de transaminasas por lo que deben buscarse otras causas.

Dentro de la enfermedades metabólicas que son causa de hepatopatía la primera a descartar por su mayor prevalencia es la hemocromatosis hereditaria $(\mathrm{HH})$.

Se trata de una de las enfermedades genéticas más frecuentes con un patrón de transmisión autosómico recesivo. En la mayoría de los casos se asocia a una mutación en el gen de la hemocromatosis denominado HFE que se localiza en el brazo corto del cromosoma 6 . Se han identificado dos mutaciones del gen HFE en pacientes con HH: La C282Y (sustitución de cisteína por tirosina en el aminoácido 282) y la H63D (sustitución de histidina por aspartato en el aminoácido 63).

En nuestro medio el $90 \%$ de los casos de $\mathrm{HH}$ son homocigotos para la mutación C282Y,el 5\% son heterocigotos compuestos $(\mathrm{C} 282 \mathrm{Y} / \mathrm{H} 63 \mathrm{D})$ y el $5 \%$ restante de los casos son $\mathrm{HH}$ no asociadas a mutaciones del HFE.

Como consecuencia de estas alteraciones tiene lugar una mayor absorción intestinal de hierro que finalmente conduce a una sobrecarga férrica progresiva en las células parenquimatosas del hígado, páncreas, corazón y otros órganos.

Ante la sospecha de $\mathrm{HH}$,el primer test que se debe realizar es el índice de saturación de transferrina (IST) por ser el índice analítico más sensible de sobrecarga férrica y la anomalía fenotípica mas precoz de $\mathrm{HH}$. Un IST $>45 \%$ asociado o no a elevación de los niveles de ferritina es indicativo de sobrecarga férrica y obliga a realizar estudio genético para descartar $\mathrm{HH}$.

La ferritina es la proteína que permite el almacenamiento de hierro en los tejidos. Su incremento no es tan precoz como el IST por lo que puede ser normal en sujetos jóvenes.

La determinación de ferritina puede utilizarse en pacientes homocigotos para la mutación C282Y/C282Y como marcador no invasivo de cirrosis. Así, la probabilidad de cirrosis en pacientes con niveles de ferritina $<1000 \mathrm{ng} / \mathrm{ml}$ es prácticamente nula mientras que hasta un $50 \%$ de los que presentan niveles por encima de $1000 \mathrm{ng} / \mathrm{ml}$ serán cirróticos.

La hepatitis autoinmune (HAI) es otra patología que puede dar lugar a un aumento moderado de transaminasas $(7,8)$. Se trata de una hepatopatía inflamatoria crónica y progresiva, de causa desconocida, cuya patogenia se atribuye a una reacción inmune frente a antígenos hepatocelulares. El hallazgo histológico característico es una hepatitis de la interfase e infiltrado inflamatorio portal a expensas principalmente de células plamáticas (9).

En las áreas donde la enfermedad presenta una mayor prevalencia como es el norte de Europa, se estima que aproximadamente 16,9 de cada 100.000 habitantes presentan la enfermedad $(10)$ con un claro predominio femenino $(3,6: 1)$ por lo que debe ser uno de los diagnósticos a tener en cuenta en mujeres con aumento de transaminasas, especialmente si presentan otras patologías autoinmunes asociadas. Dejada a su libre evolución, es una hepatopatía potencialmente grave y de mal pronóstico. Así, pacientes que padecen una forma grave de la enfermedad la tasa de mortalidad alcanza el $40 \%$ a los 6 meses del diagnóstico(9)y de los supervivientes hasta un $40 \%$ desarrollarán cirrosis(11).

Para el diagnóstico de HAI se han propuesto una serie de criterios que incluyen la exclusión de otras posibles causas de lesión hepatocelular como tóxicos, VHC, VHB, VHD o enfermerdades metabólicas (hemocromatosis, enfermedad de Wilson y déficit de a-1-antitripsina) así como la presencia de una serie de marcadores serológicos que, si bien no son específicos de la enfermadad, en su conjunto acompañados de una biopsia compatible permiten establecer el diagnóstico de esta enfermedad (Tabla I).

Las características principales que definen a la HAI son títulos de anticuerpos antinucleares (ANA) $>1: 40$ e hipergammaglobulinemia policlonal, fundamentalmente a expen- 
TABLA I

CRITERIOS DIAGNÓSTICOS DE LA HEPATITIS AUTOINMUNE

\begin{tabular}{|c|c|c|}
\hline Requisitios & Definitivo & Probable \\
\hline Enfermedades genéricas & $\begin{array}{l}\text { Fenotipo } \alpha-1 \text {-antitripsina normal. Niveles de } \\
\text { hierro, ferritina y ceruloplasmina normales }\end{array}$ & $\begin{array}{l}\text { Deficiencia parcial de } \alpha \text {-1-antitripsina. } \\
\text { Alteraciones inespecíficas en los niveles }\end{array}$ \\
\hline $\begin{array}{l}\text { Marcadores de infección } \\
\text { viral activa (VHA, VHB, } \\
\text { VHD, VHC) }\end{array}$ & Negativos & Negativos \\
\hline Tóxicos o Alcohol & $\begin{array}{l}\text { Ingesta de alcohol }<25 \mathrm{~g} / \mathrm{d} \text { y no consumo } \\
\text { reciente de fármacos hepatóxicos }\end{array}$ & $\begin{array}{c}\text { Ingesta de alcohol }<50 \mathrm{~g} / \mathrm{d} \text { y no ingesta } \\
\text { de fármacos hepatóxicos }\end{array}$ \\
\hline Laboratorio & $\begin{array}{c}\text { Elevación predominante de transaminasas, } \\
\gamma \text {-globulina o } \lg G>1,5(\mathrm{~N})\end{array}$ & $\begin{array}{l}\text { Elevación predominante de transamina- } \\
\text { sas. Hipergammaglobulinenia }\end{array}$ \\
\hline Autoanticuerpos & ANA, SMA o anti-LKM1 $>1: 80$ & ANA, SMA o anti-LKM1 > 1:40 \\
\hline Histología & $\begin{array}{l}\text { Hepatitis de la interfase. Ausencia de } \\
\text { granulomas, lesiones biliares o datos } \\
\text { sugerentes de otra enfermedad }\end{array}$ & $\begin{array}{l}\text { Hepatitis de la interfase. Ausencia de } \\
\text { granulomas, lesiones biliares o datos } \\
\text { sugerentes de otra enfermedad }\end{array}$ \\
\hline
\end{tabular}

Adaptado de Czaja et al. (7)

sas de la IgG. Otros autoanticuerpos que también se asocian a esta patología son los animúsculo liso (SMA), antimicrosomales hígado-riñón tipo 1 (anti-LKM1), anti-LC1, anti-LP o anti-SLA. Dentro de los criterios diagnósticos se incluyen parámetros histológicos por lo que ante un paciente con sospecha de hepatitis autoinmune se recomienda la realización de biopsia hepática.

Por último, la esteatohepatitis no alcoholica (EHNA) es probablemante una de las causas más frecuentes de elevación leve- moderada de transaminasas en pacientes asintomáticos.

Se caracteriza por la existencia de infiltración grasa con o sin inflamación asociada, en pacientes que no presentan un consumo de alcohol que justifique dicho hallazgos.

Los hallazgos encontrados en tejido hepático de pacientes con EHNA a los que se realiza una biopsia hepática pueden consistir en esteatosis simple, con depósito de macrovesículas de grasa en el citiplasma de los hepatocitos fundamentalmente a nivel centrolobulillar, esteatohepatitis con degeneración balonizante de los hepatocitos e infiltrado inflamatorio polimorfonuclear y grados variables de fibrosis o incluso cirrosis establecida.

$\mathrm{Su}$ verdadera prevalencia en la población todavía no está bien establecida(12) debido en gran parte a que casi la mitad de los pacientes que la padecen se encuentran asintomáticos.

Si bien la etiología y los mecanismos que intervienen en la aparición de la enfermedad no son bien conocidos, se han podido identificar una serie de factores de riesgo como son la obesidad, sexo femenino, diabetes e hiperlipidemia cuya presencia favorece la aparición de lesiones propias de EHNA. No obstante, la ausencia de dichos factores de riesgo no excluye el diagnóstico. Así, en series más recientes se ha podido comprobar que en hasta el $45 \%$ de los casos no existe ningún factor de riesgo predisponente (13).

La ausencia de test serológicos específicos para esta entidad hace que para establecer el diagnóstico sea necesario excluir otras causas de hepatopatía como son virus, enefermedades metabólicas, fármacos y fundamentalmente alcohol.

El diagnóstico será más probable en aquellas situaciones en las que el paciente se encuentra asintomático, existen uno o varios de los factores de riesgo antes mencionados con elevación predominante de la ALT y la ecografía abdominal mues- tre un hígado hiperecogénico con sombra acústica posterior.

Sin embargo, la realización de una biopsia hepática es necesaria tanto para confirmar el diagnóstico de EHNA como para poder establecer el pronóstico que tiene la enfermedad en cada caso.

Otras patologías mucho menos frecuentes que pueden dar lugar a alteración de las transaminasas son la enfermedad de Wilson y el déficit de a-1-antitripsina.

La enfermedad de Wilson es un trastorno hereditario con patrón autosómico recesivo que se caracteriza por el acúmulo de grandes cantidades de cobre en el organismo, especialmente en el hígado y cerebro.

Apoyan el diagnóstico la existencia de niveles disminuidos de ceruloplasmina en sangre $(<20 \mathrm{mg} / \mathrm{dl})$, cupremia baja $(<80 \mathrm{mg} / \mathrm{dl})$ y excreción aumentada de cobre en orina( $>100$ $\mathrm{mg} / \mathrm{dl} / 24$ horas) así como la presencia del anillo de KayserFleischer.

La prueba diagnóstica más específica es la determinación de la concentración hepática de cobre que en los individuos con enfermedad de Wilson es superior a $250 \mathrm{mg} / \mathrm{g}$.

El déficit de $\alpha$-1-antitripsina se deberá descartar en individuos con hepatopatía de causa no filiada espacialmente si existe patología pulmonar asociada como enfisema.

La primera determinación a realizar es un proteinograma que puede mostrar reducción de la fracción alfa 1-globulina. En este caso se realizará una determinación cuantitativa. En aquellos casos en los que se detecten niveles disminuidos se deberá investigar el fenotipo.

El riesgo de desarrollar enfermedad hepática es especialmente elevado para los individuos homocigotos para el fenotipo Pi ZZ aunque los heterocigotos Pi MZ, Pi SZ y Pi PZ también presentan mayor riesgo.

\section{ELEVACIÓN DE ENZIMAS DE COLESTASIS}

1. Elevación de FA (Fig. 2). La FA se produce principalmente en tejido hepático y huesos, pero también es secretada en situaciones especiales, como por ejemplo en la gestación, derivada de la placenta, sobre todo a partir del tercer trimestre de embarazo. También en individuos con grupos sanguíneos 


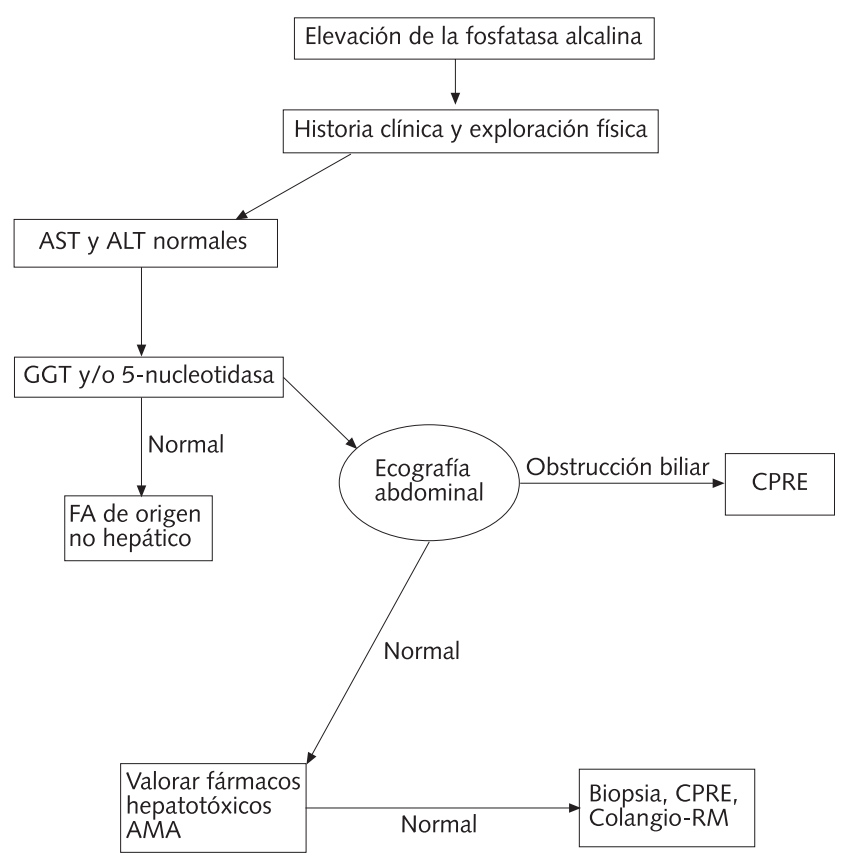

Fig. 2. Algoritmo diagnóstico para la evaluación de la alteración de la fosfatasa alcalina (FA) (Modificado de Green et al.) (21). GGT: gamma glutaril transpeptidasa; AMA: anticuerpos antimitocondriales; CPRE: colangiopancreatografía retrógrada endoscópica; Colangio-RM: colangio-resonancia magnética.

O y B pueden presentar elevaciones de la FA tras presentar una ingesta rica en grasas, incluso existen descritos casos en determinadas familias de elevaciones benignas, debido principalmente a la FA intestinal.

Por otra parte la FA sufre variaciones según la edad del paciente, encontrándose niveles elevados en adolescentes, debido al rápido crecimiento y al elevado metabolismo óseo, y a partir de los 40-65 años, sobre todo en mujeres.

Debido a todo esto, ante un paciente con niveles elevados de FA, la primera evaluación a realizar será la determinación del origen de la FA, hepática u ósea. El método más sensible y específico es la separación del isoenzima mediante electroforesis en gel de poliacrilamida, si bien este método no suele estar disponible en la práctica clínica diaria. La determinación conjunta de otras enzimas hepáticas, como la $5^{\prime}$-nuleotidasa, o más frecuentemente la gamma-glutaril transpeptidasa (GGT), son mediciones más fáciles y nos van a permitir confirmar o no el origen hepático de la FA $(14,15)$.

Normalmente la elevación de la FA, y consecuentemente de otras enzimas, como la GGT, nos va a hacer sospechar la presencia de un cuadro colestásico, es frecuente la presencia conjunta de elevación de enzimas de colestasis e hiperbilirrubinemia. Como discutiremos más adelante, existen ciertos procesos que provocaran una elevación de la bilirrubina sérica sin alteraciones en las enzimas de colestasis.

Ante una elevación leve de la FA en un paciente asintomático, la actitud más costo-efectiva es la observación del paciente $(14,15)$. Pero ante una elevación mayor o persistente de la FA, el primer paso será distinguir si esta se debe a una obstrucción al flujo biliar (colestasis extrahepática), lo que nos debe hacer sospechar en la existencia de una obstrucción biliar (de causa benigna (litiasis) o maligna (colangiocarcinoma, ampuloma, cáncer de páncreas , etc.), o bien a una alteración funcional en la producción de bilis (colestasis intrahepática), como la cirrosis biliar primaria, colangitis esclerosante primaria, fármacos, etc.

Para ello, la primera prueba diagnóstica a realizar suele ser la Ecografía abdominal. Siendo esta una prueba barata, de fácil acceso y exenta de efectos secundarios, se ha convertido en la primera prueba a realizar para confirmar o descartar la existencia de obstrucción biliar. Entre las pruebas analíticas la determinación de anticuerpos antimitocondriales (AMA), nos permitirá sospechar la presencia de una CBP, que se podría confirmar con la realización de una biopsia hepática. En aquellos pacientes que se confirme la existencia de una obstrucción biliar, la prueba de elección será la colangiopancreatografía retrógrada endoscópica (CPRE), que nos va a permitir diagnosticar la causa de obstrucción, tomar muestras y eventualmente solventar la causa de la obstrucción, bien mediante la extracción de cálculos, bien mediante la colocación de una prótesis biliar.

En aquellos pacientes con elevaciones importantes de la FA (mayor del 50\% del valor máximo de la normalidad), en los que la evaluación inicial no nos permite encontrar la causa de la elevación enzimática, se puede plantear como segunda opción la realización de técnicas de imagen, especialmente la colangio-resonancia magnética (Colangio-RM), la realización de una CPRE o de una biopsia hepática. En aquellos pacientes en los que la elevación de la FA es leve (menos del 50\% del valor superior de la normalidad), la observación antes de realizar más pruebas diagnósticas sería la mejor pauta de actuación(16).

2. Alteraciones en la Gamma-glutamil transpeptidasa $(G G T)$ : La GGT se encuentra en hepatocitos y en células del epitelio biliar, siendo una enzima muy sensible para detectar patología hepatobiliar, sin embargo es muy poco específica. Como se ha mencionado anteriormente, una de las situaciones más frecuentes de la elevación de la GGT es el consumo crónico y elevado de alcohol. De manera que la encontramos elevada en muchos otros procesos como enfermedades pancreáticas, infarto de miocardio, insuficiencia renal, EPOC, etc. Por lo tanto la GGT nos va a servir, principalmente, para evaluar la elevación de otras enzimas hepáticas, como por ejemplo la FA (17).

\section{COLESTASIS EXTRAHEPÁTICA}

La coledocolitiasis es la causa más frecuente de colestasis extrahepática, se puede presentar como un cuadro leve, con dolor en hipocondrio izquierdo, ictericia y elevación de transaminasas leve, hasta como un cuadro séptico. La CPRE es la técnica de elección, ya que como se ha dicho anteriormente nos va a permitir diagnosticar y tratar la causa de la obstrucción.

Las causas neoplásicas incluyen al páncreas, vía biliar, vesícula, ampolla de Vater o la presencia de adenopatías en el hilio hepático. La realización de una prueba de imagen como la TC, nos va a permitir además de diagnosticar la neoplasia, realizar un estudio de extensión de la misma.

La colangitis esclerosante primaria (CEP) se manifiesta con múltiples estenosis del árbol biliar, siendo la CPRE de nuevo la técnica de elección, ya que nos va a permitir identifi- 
car, si fuera posible, aquellas estenosis susceptibles de colocación de una prótesis.

En la infección por el VIH, se puede producir una colangiopatía, generalmente por infección en la vía biliar por el CMV o el cryptosporidium, presentado un cuadro similar a la CEP, con niveles de FA elevados (800 U/L) y niveles normales o ligeramente elevados de bilirrubina.

\section{COLESTASIS INTRAHEPÁTICA}

Diversas enfermedades se pueden presentar con ictericia y un patrón predominantemente colestásico. Las hepatitis virales por VHB y VHC pueden producir un cuadro de hepatitis colestásica, llamada hepatitis colestásica fibrosante. También en infecciones por otros virus como el VHA, CMV o EpsteinBarr pueden presentar un cuadro similar.

Múltiples fármacos pueden producir alteraciones colestásicas, los que más comúnmente las producen son los anabolizantes y los anticonceptivos orales. También se han asociado al uso de clorpromacina, cimetidina, eritromicina, trimetropin-sulfametoxazol y derivados de la penicilina.

La CBP aparece con más frecuencia en mujeres de mediana edad, produciendo una destrucción progresiva de los conductos biliares interlobares. Se encuentra positividad para AMA en un $95 \%$ de los pacientes.

La CEP se caracteriza por destrucción y fibrosis de los conductos biliares principales, presentando hasta en el $65 \%$ afectación de los conductos intrahepáticos. El diagnóstico se realiza mediante CPRE, siendo frecuente su asociación a enfermedad inflamatoria intestinal (EII), sobre todo Colitis ulcerosa (CU).

Otras causas más raras incluyen el síndrome del conducto biliar evanescente, la colestasis familiar benigna recurrente, colestasis asociada a la gestación, nutrición parenteral, en sepsis de origen no biliar y síndromes paraneoplásicos.

\section{HIPERBILIRRUBINEMIA AISLADA}

El primer paso para evaluar a un paciente con hiperbilirrubinemia es fraccionar esta, determinando el predominio de la forma conjugada o el de la no conjugada (Fig. 3).

\section{HIPERBILIRRUBINEMIA NO CONJUGADA}

Las enfermedades que producen un aumento de la bilirrubina indirecta se dividen en aquellas relacionadas con una producción excesiva de bilirribuna (como situaciones de hemólisis o eritropoyesis ineficaz) y alteraciones en la conjugación de la bilirrubina (como el síndrome de Gilbert o de Crigler-Najjar).

Los estados hemolíticos se diagnostican fácilmente con un frotis sanguíneo, un recuento de reticulocitos o mediante los niveles de haptoglobina. Pueden deberse tanto a patologías hereditarias como adquiridas, y la bilirrubina raramente execede de $5 \mathrm{mg} / \mathrm{dL}$. En el caso de detectar niveles superiores habría que sospechar una alteración hepática o renal coexistente al estado hemolítico.

Alteración en la captación o conjugación hepática: Para diagnosticar estas patologías es conveniente haber descartado

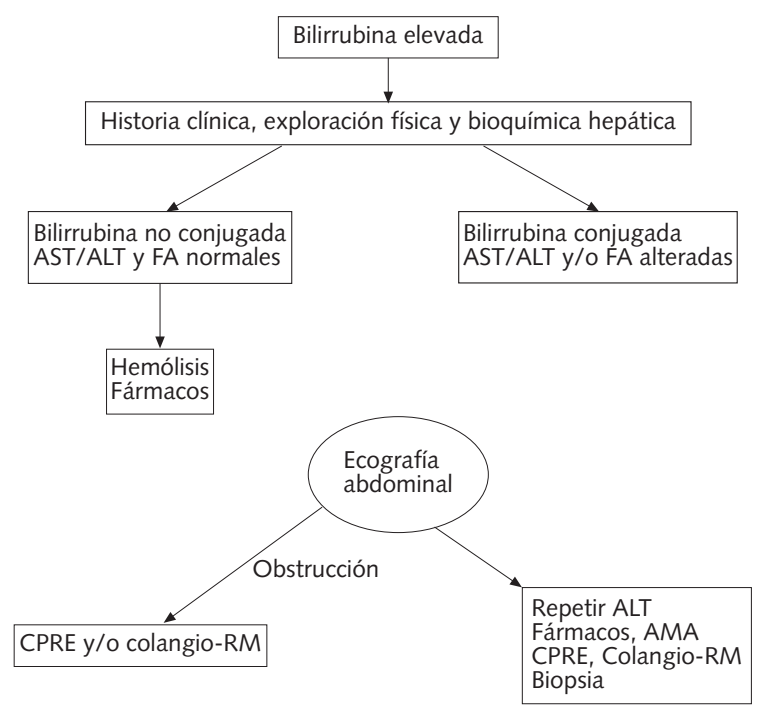

Fig. 3. Algoritmo diagnóstico para la elevación de bilirrubina sérica (Modificado de Green et al.) (21). AMA: anticuerpos antimitocondriales; FA: fosfatasa alcalina; CPRE: colangiopancreatografía retrógrada endoscópica; Colangio-RM: colangio-resonancia magnética.

primero la existencia de hemólisis. La captación de bilirrubina por los hepatocitos se puede ver alterada por la toma de fármacos (como la rifampicina y el probenecid), y más frecuentemente por el síndrome de Gilbert. Mucho menos común es la presencia de otros síndromes como el de Crigler-Najjar.

El síndrome de Gilbert afecta del 3 al 7\% de la población, con predominio de los varones. Se debe a una alteración en la enzima UDP glucoronil transferasa, presentando niveles bajos de bilirrubina (normalmente menos de $6 \mathrm{mg} / \mathrm{dL}$ ). Los niveles de bilirrubina suelen fluctuar, aumentando en situaciones de estrés, como el ayuno prolongado o con enfermedades intercurrentes. La presencia de una hiperbilirrubinemia no conjugada en un adulto sano en ausencia de hemólisis es suficiente para el diagnóstico (18).

El síndrome de Crigler-Najjar se divide en tipo I y II, según la actividad de la enzima UDP glucoronil transferasa, encontrándose disminuida en el tipo II, y siendo prácticamente nula en el tipo I. El tipo I se presenta principalmente en neonatos, con una hiperbilirrubinemia severa y kernicterus, que provocan la muerte en poco tiempo. El tipo II es algo más común, llegando los pacientes a la edad adulta. En estos pacientes es posible inducir la actividad de la enzima mediante la administración de fenobarbital a estos pacientes, disminuyendo así la hiperbilirrubinemia.

\section{HIPERBILIRRUBINEMIA CONJUGADA}

La presencia de hiperbilirrubinemia conjugada aislada, sin alteración en otras enzimas hepáticas es una situación muy rara en la práctica clínica diaria. Se encuentra fundamentalmente en dos síndromes genéticos, el síndrome de Rotor y el de Dubin-Johnson. En ambos casos presentan una ictericia 
indolora en la edad adulta. En el primero parece que hay una alteración en el almacenamiento hepático de bilirrubina, mientras que en el segundo parece deberse a una alteración en la excreción de bilirrubina en los conductos biliares. La distinción entre ambos síndromes, aunque es posible, es innecesaria debido a su evolución benigna.

\section{EVALUACIÓN DE LA FUNCIÓN HEPÁTICA}

Para evaluar la función hepática nos vamos a servir fundamentalmente de los niveles de albúmina en suero y del tiempo de protrombina. Ambos marcadores se van a ver alterados en diversas circunstancias. Así vamos a encontrar niveles disminuidos de albúmina en cuadros malabsortivos, malnutrición, enfermedades graves, nefrosis, etc. Y el tiempo de protrombina se va a ver afectado en diversos cuadros hematológicos o en deficiencias nutricionales. A pesar de todo, y siempre acompañados del contexto clínico adecuado, van a ser unos buenos marcadores de función hepática. Además, la vida media de la albúmina es de 19 a 21 días, mientras que la mayor parte de los factores de la coagulación tienen una vida media de menos de un día. Por lo tanto, nos van a permitir diferenciar procesos agudos de hepatopatías crónicas $(19,20)$.

\section{¿CUÁNDO REALIZAR UNA BIOPSIA HEPÁTICA?}

Esta es una pregunta de difícil respuesta. La biopsia hepática es una técnica sencilla, pero no exenta de complicaciones. Se estima que el riesgo de presentar una complicación grave es de entre un 0,1 a un $0,3 \%$ con una tasa de mortalidad de 9/100000. Por lo tanto, la decisión de realizar una biopsia hepática debe de ser individualizada, evaluando el riesgobeneficio en nuestro paciente, siendo de especial utilidad en pacientes con niveles elevados de transaminasas de forma crónica (más de tres meses) (16).

\section{PARÁMETROS QUE VALORAN LA FUNCIÓN HEPÁTICA}

Los parámetros analíticos que nos van a permitir evaluar la función del hígado son: los niveles de albúmina en suero, la bilirrubina y el tiempo de protrombina.

Entre las funciones más importantes del hígado se incluyen el metabolismo y la eliminación de bilirrubina. De este modo, la elevación de bilirrubina tiene valor pronóstico tanto en la enfermedades hepáticas agudas como en hepatopatías crónicas

La albúmina el la proteína sérica más importante sintetizada en el hígado. Tiene una vida media de 20 días por lo que no suele disminuir en cuadros agudos. Por el contrario, en hepatopatías crónicas avanzadas se produce hipoalbuminemia debido tanto a una disminución en su síntesis, como a la hemodilución y malnutrición que se produce en estos casos. Así, es uno de los parámetros analíticos junto con la bilirrubina y el tiempo de protrombina que se emplean para el estadiaje de la cirrosis en la clasificación de Child-Pugh y que permite establecer una aproximación pronóstica en estos pacientes.

Entre las funciones más importantes del hígado se incluyen el metabolismo y la eliminación de bilirrubina. De este modo, la elevación de bilirrubina tiene valor pronóstico tanto en la enfermedades hepáticas agudas como en hepatopatías crónicas.

La alteración del tiempo de protrombina (TP) en las enfermedades hepatobiliares puede ser debido tanto a déficit de vitamina $\mathrm{K}$, ya que al ser una vitamina liposoluble su absorción se encuentra disminuida por la colestasis, como a déficit en su síntesis en situaciones de insuficiencia hepática .Tienen una vida media corta por lo que el TP es un parámetro fundamental con elevado valor pronóstico en la insuficiencia hepática aguda.

\section{CONCLUSIÓN}

No existen estudios prospectivos doble ciego que valoren la eficacia de los test de función hepática, sólo existen unos pocos estudios no controlados y varias revisiones sobre el tema. Las recomendaciones que encontramos en estos estudios suelen ser por tanto, de poca calidad.

El primer paso en la valoración de un paciente con alteración de las pruebas de función hepática debe ser una historia clínica y una exploración física cuidadosa. La presencia de signos y síntomas, la presencia de factores de riesgo o la historia de consumo de tóxicos o de medicamentos es de vital importancia.

La realización de pruebas diagnósticas no invasivas, parece indicada en la mayoría de los pacientes con elevaciones persistentes de las transaminasas, aunque se encuentren asintomáticos. La realización de serologías virales o de un perfil férrico sería adecuado para pacientes con elevaciones de la ALT. Si estos son negativos habría que descartar otras causas como enfermedad autoinmune o metabólica. La realización de una Ecografía abdominal nos va a permitir visualizar de forma sencilla el parénquima hemático y el sistema biliar, siendo de especial utilidad en pacientes con predominio colestásico. $\mathrm{Si}$ a pesar de esto no se consigue clarificar el origen de la elevación de loas pruebas de función hepática, se deben realizar otras pruebas diagnósticas, serológicas o de imagen, pudiendo recurrir en última instancia a la biopsia hepática para clarificar el origen de estas alteraciones.

\section{AGRADECIMIENTOS}

Este trabajo ha sido realizado gracias a una beca (C03/C02) concedida por el Instituto Carlos III, Madrid. España. 


\section{Bibliografía}

1. Scola RH, Werneck LC, Prevedello DM, Toderke EL, Iwamoto FM Diagnosis of dermatomyositis and polymyositis: a study of 102 cases. Arq Neuropsiquiatr 2000; 58: 789-99.

2. Lin YC, Lee WT, Huang SF, Young C, Wang PJ, Shen YZ. Persistent hypertransaminasemia as the presenting findings of muscular dystrophy in childhood. Acta Paediatr Taiwan 1999; 40: 424-9.

3. Mathiesen UL, Franzen LE, Fryden A, Foberg U, Bodemar G. The clinical significance of slightly to moderately increased liver transaminase values in asymptomatic patients. Scand J Gastroenterol 1999; 34: 85-91.

4. Lewis JH. Drug-induced liver disease. Med Clin North Am 2000; 84 1275-311, x.

5. McQuillan GM, Townsend TR, Fields HA, Carroll M, Leahy M, Polk BF. Seroepidemiology of hepatitis B virus infection in the United States. to 1980. Am J Med 1989; 87: 5S-10S.

6. Proceedings of the European Association for the Study of the Liver International Consensus Conference on Hepatitis B. September 14-16, Geneva, Switzerland. J Hepatol 2003;39 Suppl 1: S1-235.

7. Czaja AJ. Autoimmune hepatitis. Evolving concepts and treatment strategies. Dig Dis Sci 1995; 40: 435-56.

8. Krawitt EL. Autoimmune hepatitis. N Engl J Med 1996; 334: 897-903.

9. Soloway RD, Summerskill WH, Baggenstoss AH, Geall MG, Gitnick GL, Elveback IR, et al. Clinical, biochemical, and histological remission of severe chronic liver disease: a controlled study of treatments and early prognosis. Gastroenterology 1972; 63: 820-33

10. Boberg KM, Aadland E, Jahnsen J, Raknerud N, Stiris M, Bell H. Incidence and prevalence of primary biliary cirrhosis, primary cholangitis, and autoimmune hepatitis in a Norwegian population. Scand J Gastroenterol 1998; 33: 99-103.

11. Mistilis SP, Skyring AP, Blackburn CR. Natural history of active chronic hepatitis. I. Clinical features, diagnostic criteria, morbidity, morta- lity and survival. Australas Ann Med 1968; 17: 214-23.

12. Reid AE. Nonalcoholic steatohepatitis. Gastroenterology 2001; 121 710-23.

13. Bacon BR, Farahvash MJ, Janney CG, Neuschwander-Tetri BA. Nonalcoholic steatohepatitis: an expanded clinical entity. Gastroenterology 1994; 107: 1103-9.

14. Amberg JM, Schneiderman LJ, Berry CC, Zettner A. The abnormal outpatient chemistry panel serum alkaline phosphatase: analysis of physician response, outcome, cost and health effectiveness. J Chronic Dis 1982; 35: 81-8

15. Lieberman D, Phillips D. "Isolated" elevation of alkaline phosphatase: significance in hospitalized patients. J Clin Gastroenterol 1990; 12 : 415-9.

16. Sorbi D, McGill DB, Thistle JL, Therneau TM, Henry J, Lindor KD. An assessment of the role of liver biopsies in asymptomatic patients with chronic liver test abnormalities. Am J Gastroenterol 2000; 95: 3206-10.

17. Moussavian SN, Becker RC, Piepmeyer JL, Mezey E, Bozian RC. Serum gamma-glutamyl transpeptidase and chronic alcoholism. Influence of alcohol ingestion and liver disease. Dig Dis Sci 1985; 30: 211-4.

18. Monaghan G, Ryan M, Seddon R, Hume R, Burchell B. Genetic variation in bilirubin UPD-glucuronosyltransferase gene promoter and Gilbert's syndrome. Lancet 1996; 347: 578-81.

19. Doumas BT, Peters T, Jr. Serum and urine albumin: a progress report on their measurement and clinical significance. Clin Chim Acta 1997; 258 (1): 3-20.

20. Harrison PM, O'Grady JG, Keays RT, Alexander GJ, Williams R. Seria prothrombin time as prognostic indicator in paracetamol induced fulminant hepatic failure. Bmj 1990; 301: 964-6.

21. Green RM, Flamm S. AGA technical review on the evaluation of liver chemistry tests. Gastroenterology 2002; 123: 1367-84. 